\title{
Therapeutic Effectiveness of Nutrition Therapy in Pediatric Patients with Chronic Liver Diseases Awaiting Liver Transplantation
}

\author{
Marco Giammanco ${ }^{1}$, Silvana Bavetta ${ }^{2}$, Rossella Greco ${ }^{3}$, Danila Di Majo ${ }^{1} \&$ Maurizio La Guardia ${ }^{1}$ \\ ${ }^{1}$ Unità di Fisiologia e Farmacologia, Dipartimento DISMOT, Università di Palermo, via A. Elia 3, Palermo, \\ Italy \\ ${ }^{2}$ Istituto Mediterraneo per i Trapianti e Terapie ad Alta Specializzazione - ISMETT, University of Pittsburgh \\ Medical Center, Palermo, Italy \\ ${ }^{3}$ Department of Economics, Boston College, 140 Commonwealth Avenue, Chestnut Hill, MA, USA \\ Correspondence: Marco Giammanco, Department DISMOT, University of Palermo Via A. Elia1, Palermo 90127, \\ Italy. Tel: 39-623-6403. E-mail: marco.giammanco@unipa.it
}

Received: October 25, 2012 Accepted: December 5, 2012 Online Published: January 28, 2013

doi:10.5539/jfr.v2n1p179

URL: http://dx.doi.org/10.5539/jfr.v2n1p179

\begin{abstract}
It is important to prevent protein/calorie malnutrition in children with end stage liver diseases prior to transplantation. This study involved 34 patients between the ages of 10 and 156 months (mean value 25.69 months \pm 32.2 ) (13 females and 21 males) on the liver transplant waiting list. Data collected as of three months before transplant and up to ten months after the procedure concerned gender, age, weight, height, Pediatric End Stage Liver Disease Score, baseline pathology, type of nutrition, type of transplant, immunosuppression, pulse steroid therapy, length of stay, and post transplant complications. Linear regression analysis showed that the length of hospital stay was 24.5 days more for females than for males, but also that intensive nutrition therapy shortens this stay for both female patients $(P=0.085)$ and younger patients $(P=0.023)$. The study population was divided into two groups according to the different nutritional therapies adopted. The Student's t-test and Mann-Whitney test evidenced that the group receiving intensive nutrition therapy grew taller compared with the group following an oral diet (mean -1.37 and Prob $=0.043$ ); that females grew taller compared to males (mean $-1.65+/-0.56)$; and that there was an increase in height among the children in the group receiving intensive nutrition therapy despite the presence $(-1.37+/-0.56)$ or absence $(-14.8+/-5.44$ and Prob $=0.035)$ of complications, and despite the administration $(-1.03+/-0.33)$ or non administration $(-1.48+/-0.55$ and Prob $=$ 0.019) of steroids. Intensive nutrition therapy enhances the velocity of growth in height and shortens the length of hospital stay, thus optimizing the final prognosis of the baseline pathology.
\end{abstract}

Keywords: nutrition therapy, pediatric patients, liver transplantation

\section{Introduction}

Malnutrition is a complication of chronic hepatic failure that significantly affects the prognosis of the pathology because it inhibits physical growth (De Russo, Ye, \& Shepherd, 2007; Barshes, Chang, Karpen, Carter, \& Goss, 2006; Giammanco et al., 2003) and mental development, and lengthens the post-surgery recovery period with higher rate of complications (Alonso, 2008; Bucuvalas, Zeng, \& Anand, 2004).

Considerable research progress has been made in explaining the relationship between pretransplant nutritional status and posttransplant outcomes in pediatric liver transplant recipients.

Protein-calorie malnutrition should be anticipated and prevented by early intervention with intensive nutritional support in the pretransplant period.

This study aims at describing how proper nutritional therapy should be adjusted according to the nutritional screening of the pediatric patient, along with the intake of specific nutrients, eventually improving statural growth and reducing length of stay.

As the study focuses on the influence of nutrition, the population was assessed on the basis of nutritional status and of the different nutritional therapies adopted, so as to assess whether outcomes changed accordingly. 


\section{Patients and Methods}

\subsection{Study Population and Data Collection}

The study involved 34 subjects ( $13 \mathrm{f}$ and $21 \mathrm{~m}$ ) between the ages 10 and 156 months (mean value 25.69 months \pm 32.2 ) on the ISMETT (Istituto Mediterraneo per i Trapianti e Terapie ad Alta Specializzazione) liver transplant waiting list between November 2006 and December 2008.

Data was collected as of three months before transplant and up to ten months after the procedure, specifically: gender, age, average daily weight and Z-score, average height and Z-score, Pediatric End Stage Liver Disease (PELD) Score (Bourdeaux et al., 2005; McDiarmid, Merion, Dykstra, \& Harper, 2004) baseline pathology, surgical interventions before transplant, nutritional screening and evaluation, type of pre- and post-transplant nutrition, type of transplant, immunosuppression protocol and pulse steroid therapy, length of hospital stay, and post-transplant complications (Table 1).

Table 1. Characteristics of sample group (number of patients 34)

\begin{tabular}{|c|c|}
\hline Age & Gender \\
\hline$<12$ months $11(32.3 \%)$ & (Females \%) $13(38.2 \%)$ \\
\hline 13-24 months $10(29.4 \%)$ & $\underline{\text { Race }}$ \\
\hline 25-156 months 13 (38.2\%) & (Europeans \%) 28 (82.3\%) \\
\hline Pre-transplant procedures & Intensive nutrition \\
\hline \multirow[t]{3}{*}{$15(44.1 \%)$} & $19(55,9 \%)$ \\
\hline & $($ Enterale + Oral) $15(78.9 \%)$ \\
\hline & $($ Enteral + Oral + Parenteral $) 4(21.0 \%)$ \\
\hline \multicolumn{2}{|l|}{ Type of transplant } \\
\hline Split II-III 27 (79.4\%) & Whole liver $5(14.7 \%)$ \\
\hline Split I-IV-VIII 2 (5.9\%) & Redo-split $3(8.8 \%)$ \\
\hline \multicolumn{2}{|l|}{ Post-transplant complications } \\
\hline Infections $6(17.6 \%)$ & Biliary $3(8.8 \%)$ \\
\hline Rejection 4 (11.7\%) & No complications $14(41.1 \%)$ \\
\hline \multicolumn{2}{|l|}{ Vascular $6(17.6 \%)$} \\
\hline Standard immunosuppression & Pulse steroids therapy \\
\hline $26(76.5 \%)$ & $8(23.5 \%)$ \\
\hline \multicolumn{2}{|l|}{ Pathology } \\
\hline Biliary atresia $26(76.4 \%)$ & Alpha $_{1}$ antitrypsin deficiency $1(2.9 \%)$ \\
\hline Wilson's syndrome 1 (2.9\%) & Alagille syndrome $1(2.9 \%)$ \\
\hline Hepatoblastoma 1 (2.9\%) & Other $4(11.7 \%)$ \\
\hline \multicolumn{2}{|l|}{ PELD score } \\
\hline$<1816(47 \%)$ & $>1818(52.9 \%)$ \\
\hline \multicolumn{2}{|l|}{$\underline{\text { LOS in days }}$} \\
\hline > $3022(64.7 \%)$ & $<3012(35.2 \%)$ \\
\hline
\end{tabular}

\subsection{Statistical Analysis}

Linear and logistic regression analyses were used to correlate the two dependent variables, length of stay and complications, with 11 independent variables. The values considered significant were $\mathrm{P}<0.5$ and $<0.1$.

Student's t-test and the non-parametric two-tailed Mann-Whitney $U$ test were applied to the two groups on different nutritional plans, and subdivided into four additional subgroups on the basis of gender, complications, immunosuppression therapy, and high-dose steroid therapy. The t-test will evidence the difference between the 
mean values of the variables, while the Mann-Whitney test will show the sum of the theoretical and actual ranks. With regard to the Mann-Whitney test, we wanted to differentiate two distributions - treated children vs. non-treated children - meaning Prob $<1 \mathrm{z} l=0.05$. In the presence of two different distributions, it is necessary to verify which group's performance is better or worse than expected. If the sum of ranks of a group is lower than expected, this means that the group ranks higher than expected and vice versa. Therefore, as far as outcomes are concerned (body weight, height, velocity of growth, complications), our goal is for the sum of ranks of the children subject to treatment to be lower than expected (and therefore rank higher), and for the opposite to occur for the length of hospital stay.

We also applied the t-test and the Mann-Whitney U test, dividing the population into two groups by type of transplant (cadaveric split-liver, segments II - III) and living-related split-liver, cadaveric whole organ, split I-IV and VIII and redo-cadaveric split-liver segments II - III.

\subsection{Independent Variables}

Gender: there were 13 females, 10 of whom were between the $3^{\text {rd }}$ and $10^{\text {th }}$ percentile, and 3 above the $10^{\text {th }}$ percentile; and 21 males, 9 of whom between the $3^{\text {rd }}$ and $10^{\text {th }}$ percentile, and 12 above the $10^{\text {th }}$ percentile.

Age: age ranged between 10 and 156 months at the time of transplant (mean value 25.69 months \pm 32.2 ). Eleven children (32.3\%) were below the age of 12 months; 10 children (29.4\%) between 12 and 24 months of age; and 13 children (38.2\%) between 25 and 156 months of age. Z-scores were used for height and weight to eliminate age differences.

Body weight and height: the children's growth was calculated on the basis of daily body weight and height (absolute values, percentages and Z-scores), measured 3 months before transplant, at the time of transplant, and 10 months after transplant.

$$
\text { Height Zscore }=\frac{\mathrm{x}-\mu}{\sigma}
$$

As part of the study we calculated the pre- and post-transplant velocity of growth by modifying the Tanner formula (Tanner, Whitehouse, \& Takaishi, 1966) and using height as the reference value:

$$
\begin{aligned}
& Z \text { velocity }_{\text {pre tx }}=\left(\text { height }_{\mathrm{tx}}-\text { height }_{\text {pre tx }}\right)-\left(\text { height } 50^{\text {th }}{ }_{\text {age tx/gender }}-\text { height } 50^{\text {th }}{ }_{\text {age pre tx/ gender }}\right) \\
& Z \text { velocity post tx }=\left(\text { height }_{\text {post tx }}-\text { height }_{\mathrm{tx}}\right)-\left(\text { height } 50^{\text {th }} \text { age post tx/ gender }- \text { height } 50^{\text {th }}{ }_{\text {age tx/ gender }}\right)
\end{aligned}
$$

Pathology and pre-transplant procedures: the study takes into account the following pathologies, all of which imply malabsorption and therefore slow down or stop growth: 26 cases of biliary tract atresia; 1 case of Wilson's disease; 1 of hepatoblastoma; 1 of alpha1-antitrypsin deficit; 1 of Alagille syndrome; 1 of neonatal sclerosing cholangitis; 1 of congenital hepatic fibrosis; 1 of autoimmune hepatitis; and 1 of anicteric cholestasis.

Of the 34 children, 23 of those affected by biliary atresia underwent a Kasai procedure; 3 underwent a redo-transplant; 2 underwent a transplant in a different facility; 1 received cycles of chemotherapy; and 8 did not undergo any pre-transplant procedure.

The pre-transplant daily nutritional support, equal to $130-150 \%$ of the basal energy expenditure (Alonso, 2008; Greer, Lehnert, Lewindon, Cleghorn, \& Shepherd, 2003; Novy, \& Schwarz, 1997; Shepherd, 1996; Ramaccioni, Soriano, Arumugam, \& Klish, 2000; Heubi, Helman, Melvin, \& Shulman, 2002; Campos, Matias, \& Coelho 2002; Falcão \& Tannuri, 2002), consisted of the supply of a lipid emulsion of long-chain triglyceride/medium-chain triglyceride in a ratio of 3:2, liposoluble vitamins, and micronutrients (Johnson, Young, Cotter, Lin, \& Rowe, 1990; Lai \& Chen, 2000; Marchesini, Fabbri, Bianchi, Brizi, \& Zoli, 1996). Oral intake was the administration route of preference. If it failed to generate body weight gain, oral nutrition was integrated with cycles of enteral nutrition so as to reach the nutritional goals, administered via NG tube or gavage according to tolerance, and by gradually increasing formula volumes and concentrations. If the enteral route was not practicable, or if there was onset of complications, we administered parenteral nutrition (Holt, Miell, Jones, Mieli-Vergani, \& Baker, 2000; Shepherd et al., 1991).

Of the 34 children, 19 with weight and height between the $3^{\text {rd }}$ and $10^{\text {th }}$ percentile followed the intensive nutrition protocol, which calls for the alternation of oral nutrition and enteral nutrition, and at times (4 subjects) even parenteral nutrition. The other 15 children with weight and height between the $25^{\text {th }}$ and $90^{\text {th }}$ percentile followed an enriched and controlled oral diet.

Immunosuppression: consisted of a dose of steroids $(10 \mathrm{mg} / \mathrm{kg}$ of metilprednisolone IV) and 10-20 $\mathrm{mg}$ of intra-op basiliximab IV, followed by another dose of basiliximab on the 4th day after transplantation. In addition, 
daily doses of tacrolimus $(0.04 \mathrm{mg} / \mathrm{kg}$ BID PO) were given in order to reach the following blood trough levels: $10-15 \mathrm{ng} / \mathrm{mL}$ during the first month after transplant, $5-10 \mathrm{ng} / \mathrm{mL}$ between the $2^{\text {nd }}$ and $6^{\text {th }}$ month post-transplant, and $3-5 \mathrm{ng} / \mathrm{mL}$ thereafter as maintenance therapy.

This protocol can vary depending on side effects (tacrolimus-related nephrotoxicity and neurotoxicity), on whether the donor or recipient suffer from particular pathologies, or on preexisting immunosuppression therapies, such as mycophenolate mofetil $\left(450 \mathrm{mg} / \mathrm{m}^{2} /\right.$ dose for 2 weeks followed by $350 \mathrm{mg} / \mathrm{m}^{2} /$ dose $)$ or cyclosporine $(10-15 \mathrm{mg} / \mathrm{kg}$, doses adjusted in order to reach blood trough levels of $100-400 \mathrm{ng} / \mathrm{ml})$.

The hospital length of stay was longer than 30 days for 22 children (64.7\%), and less than 30 days for 12 children (35.3\%).

Complications: recorded during the ten months after transplantation were acute rejection (n. $4=11.7 \%$ ); biliary complications (n. $3=8.8 \%$ ); vascular complications such as hepatic artery and portal vein thrombosis $(\mathrm{n} .6=$ $17.6 \%)$; viral, bacterial and fungal infections (n. $6=20.6 \%)$; other complications $(8=23.5 \%)$; and death from cardiac arrest and infections $(3=8.8 \%)$. There were no complications in 14 cases $(41.1 \%)$, while "other complications" also included those that are not peculiar to liver transplantation.

\section{Results}

By applying linear regression analysis between the length-of-stay dependent variable and the 11 independent variables,

$$
\begin{gathered}
\mathrm{LOS}=\beta_{0}+\beta_{1 \text { PELD }}+\beta_{2 \text { gender }}+\beta_{3 \text { Z-score h }}+\beta_{4 \text { Z-score w }}+\beta_{5 \text { nutrition }}+\beta_{6 \text { transplant }}+\beta_{7 \text { age at transplant }}+\beta_{8 \text { immunosuppression }}+ \\
\beta_{9 \text { complications }}+\beta_{10 \text { intensive nutrition females }}+\beta_{11 \text { intensive nutrition per age }}
\end{gathered}
$$

where $\beta_{0}$ is a constant, and $\beta_{1}$ through $\beta_{11}$ are the coefficients of the indicated variables, we observed two significant outcomes $(p>0.05)$ related to gender and age (Table 2$)$.

Table 2. Linear correlation between LOS and 11 variables from admission to T5

\begin{tabular}{llllll}
\hline LOS & Coef. & Standard error & $\mathrm{P}>|\mathrm{t}|$ & $95 \%$ Confidence & Interval \\
\hline 33 observations & & & & & \\
Pediatric end-stage liver disease & 0.1964 & 0.36722 & 0.598 & -0.5672 & 0.9600 \\
Gender & 24.5110 & 11.7183 & 0.049 & -0.1415 & 48.8806 \\
Height Z-score & 3.6345 & 2.3409 & 0.135 & -1.2336 & 8.5027 \\
Weight Z-score & 1.4924 & 2.3790 & 0.537 & -3.4550 & 6.4400 \\
Intensive nutrition & -15.6643 & 11.3181 & 0.181 & -39.2016 & 7.8730 \\
Transplant & -11.2817 & 8.9494 & 0.221 & -29.8932 & 7.3297 \\
Age at the time of tx & -0.16003 & 0.1151 & 0.179 & -0.3994 & 0.0793 \\
Immunosuppression & 10.01194 & 8.6308 & 0.259 & -7.9369 & 27.9608 \\
Complications & 10.5472 & 6.2240 & 0.105 & -2.3963 & 23.4907 \\
Intensive nutrition in females & -24.6405 & 13.6134 & 0.085 & -52.9511 & 3.6701 \\
Intensive nutrition per Age & 0.7564 & 0.3094 & 0.023 & 0.1184 & 1.4000 \\
Constant & 25.6633 & 15.1718 & 0.106 & -5.8881 & 57.2148 \\
\hline
\end{tabular}

The first outcome indicates that the mean length of stay for females is 24.5 days (value of the coefficient) longer than for males; the second outcome indicates different lengths of stay for each additional year of age. Intensive nutrition works better on younger children by shortening their length of stay, and positively affects females as it decreases their days of hospitalization by approximately 24.6 days (value of the coefficient) $(\mathrm{P}<0.10)$.

Furthermore, the results showed that intensive nutrition, though not statistically significant, reduced the mean length of stay. This means that the children receiving intensive nutrition had a shorter length of stay. Unfortunately the small sample size did not allow for a confirmation of this outcome statistically, which would require a larger sample and a longer time interval. By applying logistic regression analysis, as well, we compared 
the post-transplant dependent variable (complications) with the 10 independent variables indicated above, but were unable to identify any predictor of complications (Table 3 ).

Table 3. Correlation between complications and peri-operative variables from admission to T5

\begin{tabular}{llllll}
\hline Complications & Coef. & Standard error & $\mathrm{P}>|\mathrm{z}|$ & $95 \%$ Confidence & Interval \\
\hline 33 observations & & & & & \\
pediatric end-stage liver disease & 0.3638 & 0.0574 & 0.527 & -0.0762 & 0.1490 \\
gender & 0.57312 & 1.9375 & 0.767 & -4.3707 & 3.2244 \\
height Z-score & -0.2693 & 0.4203 & 0.522 & -1.0931 & 0.5545 \\
weight Z-score & -0.0044 & 0.3239 & 0.989 & -0.6393 & 0.6304 \\
intensive nutrition & -0.8636 & 1.9057 & 0.650 & -2.8715 & 4.5989 \\
transplant & -1.4201 & 1.5719 & 0.366 & -4.5010 & 1.6608 \\
Age at transplant & -0.0275 & 0.0193 & 0.155 & -0.0655 & 0.0103 \\
immunosuppression & 2.5227 & 1.7505 & 0.150 & -0.9082 & 5.9538 \\
intensive nutrition in females & -0.2467 & 2.2275 & 0.912 & -4.1192 & 4.6126 \\
intensive nutrition per age & 0.0513 & 0.0439 & 0.907 & -0.0809 & 0.9126 \\
constant & 1.1186 & 2.4231 & 0.644 & -3.6306 & 5.8679 \\
\hline
\end{tabular}

In this analysis we took into consideration 10 independent variables and excluded the length of stay because the presence of complications implies a longer hospitalization.

$$
\begin{gathered}
\text { Complications }=\beta_{0}+\beta_{1 \text { PELD }}+\beta_{2 \text { gender }}+\beta_{3 \text { Z-score } \mathrm{h}}+\beta_{4 \text { Z-score } \mathrm{w}}+\beta_{5 \text { nutrition }}+\beta_{6 \text { transplant }}+\beta_{7 \text { age at transplant }}+ \\
\beta_{8 \text { immunosuppression }}+\beta_{9 \text { intensive nutrition females }}+\beta_{10 \text { intensive nutrition per age }}
\end{gathered}
$$

The 34 children were divided into two groups: Group 0, consisting of $19(55.8 \%)$ severely malnourished children subject to an intensive nutrition protocol (oral diet + enteral nutrition), 4 of whom also received parenteral nutrition, and Group 1 consisting of 15 children $(44.2 \%)$ with a height above the $25^{\text {th }}$ percentile following an oral diet alone.

As regards the t-test, the statistically significant factor (Table 4) regards the height $Z$-score from admission to post-transplantation. Intensive nutritional therapy increased height in the patients in Group 0.

Table 4. T-Test performed on the 2 groups following different nutrition protocols

\begin{tabular}{llllll}
\hline & $\begin{array}{l}\text { Group 0-Group 1 } \\
\text { (mean) }\end{array}$ & Standard error & $\begin{array}{l}95 \% \\
\text { Confidence }\end{array}$ & Interval & P value \\
\hline LOS & 0.94 & 6.66 & -13.60 & 13.79 & $\mathrm{NS}$ \\
Height Z-score & -1.37 & 0.45 & -2.29 & -0.44 & $\mathrm{~S}$ \\
weight Z-score & -0.28 & 0.46 & -1.23 & 0.66 & $\mathrm{NS}$ \\
pre-tx speed of growth & -0.37 & 1.24 & -2.90 & 2.15 & $\mathrm{NS}$ \\
post-tx speed of growth & -7.83 & 5.17 & -18.66 & 2.98 & $\mathrm{NS}$ \\
complications & -0.98 & 0.17 & -0.45 & 0.25 & $\mathrm{NS}$ \\
\hline
\end{tabular}

In parallel, the Mann-Whitney test showed a significant increase in both height Z-score and height percentage among the patients receiving intensive nutrition compared to the patients receiving the oral diet alone (Table 5). 
Table 5. Mann-Whitney Test: rank sums of the 2 groups following different nutrition protocols

\begin{tabular}{ll}
\hline & Prob $>1 \mathrm{z}$ \\
\hline LOS & 0.42 \\
absolute value of height & 0.09 \\
Height Z-score & 0.043 \\
Percentage height & 0.03 \\
pre-tx speed of growth & 0.66 \\
post-tx speed of growth & 0.02 \\
complications & 0.86 \\
absolute value of weight & 0.31 \\
weight Z-score & 0.51 \\
percentage weight & 0.22 \\
\hline
\end{tabular}

We further divided each of the two groups into 4 subgroups according to gender, complications, immunosuppression, and high dose steroid therapy, and applied the t-test and Mann-Whitney test.

Comparison of the gender-related differences between the average values of the two groups receiving different types of nutrition showed that the females (3 in Group 0 , and 10 in Group 1) receiving intensive nutrition grew more in height and body weight compared to the males (12 in Group 0, and 9 in Group 1) (Table 6), as reflected in their increase in height $\mathrm{Z}$-score and percentage body weight.

Table 6. T-Test performed on the 2 groups following different nutrition protocols and subgroups

\begin{tabular}{llllll}
\hline & Subgroups & $\begin{array}{l}\text { Group 0 } \\
- \text { Group 1 } \\
\text { (mean) }\end{array}$ & Standard error & 95\% Confidence & Interval \\
\hline Height Z-score & $\begin{array}{l}\text { Gender } \\
\text { (females) }\end{array}$ & -1.65 & 0.56 & -2.91 & -3.99 \\
Percentage weight & $\begin{array}{l}\text { Gender } \\
\text { (females) }\end{array}$ & -47.32 & 19.26 & -92.71 & -1.93 \\
Percentage height & $\begin{array}{l}\text { Without } \\
\text { complications }\end{array}$ & -14.88 & 5.44 & -26.79 & -2.98 \\
Height Z-score & $\begin{array}{l}\text { With } \\
\text { complications }\end{array}$ & -1.37 & 0.56 & -2.55 & -0.19 \\
Height Z-score & $\begin{array}{l}\text { Standard } \\
\text { immunosuppression }\end{array}$ & -1.64 & 0.59 & -2.94 & -0.34 \\
protocol & & & & \\
Height Z-score & Without steroid therapy & -1.48 & 0.55 & -2.64 & -0.33 \\
Height Z-score & With steroid therapy & -1.03 & 0.33 & -1.85 & -0.19 \\
Percentage weight & With steroid therapy & -53.69 & 14.85 & -91.18 & -16.2 \\
\hline
\end{tabular}

Likewise, the same occurred with the other test, with a significant increase in absolute values of female height and percentage values (Table 7). 
Table 7. Mann-Whitney Test: rank sums of the 2 groups following different nutrition protocols and subgroups

\begin{tabular}{lll}
\hline & Subgroups & Prob > 1 z 1 \\
\hline Absolute value of height & Gender (females) & 0.042 \\
Percentage height & Gender (females) & 0.0425 \\
Percentage height & Without & 0.0350 \\
& complications & \\
Height Z-score & Standard immunosuppression protocol & 0.0070 \\
Height Z-score & Without high steroid doses & 0.0190 \\
\hline
\end{tabular}

Groups 0 and 1 were divided into two subgroups, one with complications ( 8 children from Group 0 , and 12 children from Group 1), and one without complications (7 children from each Group). The t-test (Table 6) and the Mann-Whitney test (Table 7) showed that intensive nutrition therapy positively affected the growth in height (percentage and Z-score) in both groups with and without complications.

As regards the immunosuppression subgroup, the statistically significant values regard the subgroup that followed the standard protocol, since the small dimensions of the subgroup following the non-standard protocol did not allow for any measurable results. Among the patients receiving standard immunosuppression, those receiving intensive nutrition grew taller compared to those following a controlled oral diet alone (Table 6). In parallel, the Mann-Whitney test applied to the group receiving standard immunosuppression showed a significantly higher height $Z$-score in those receiving intensive nutrition (Table 7).

The acute rejection experienced by 3 children was treated with a cycle of high dose steroid therapy for 3-6 days, gradually reduced based on improvement, in order to show if and how high steroid doses administered in case of rejection affect growth (Tables 6 and 7). The outcomes achieved with the t-Test showed the positive effect of intensive nutrition on the growth in height regardless of steroid therapy, and the outcome of the Mann-Whitney test was significant in relation to height in the group not subject to steroid therapy.

In our study population of 34 children there were 27 split-liver procedures segments II-III (79.4\%), 24 of which were cadaveric, and 3 of which were retransplants. In addition, there were 5 whole-liver transplants (14.7\%); and 2 split-liver right lobe segments I-IV-VIII (5.9\%). We also divided the study population according to the type of transplant in Group 1, consisting of 24 children who underwent cadaveric split-liver transplant segments II-III, and Group 0 , consisting of 10 children who underwent other types of transplants. When we applied the t-test and Mann-Whitney test, the outcomes showed a height increase among the group of cadaveric split-liver transplants of segments II-III compared to the group subject to other types of transplants (Tables 8 and 9).

Table 8. T-Test performed on the 2 groups subject to different transplants

\begin{tabular}{llllll}
\hline & $\begin{array}{l}\text { Group 0 } \\
- \text { Group 1 } \\
\text { (mean) }\end{array}$ & Standard error & $\begin{array}{l}95 \% \\
\text { Confidence }\end{array}$ & Interval & P value \\
& -3.1 & 3.71 & -10.66 & 4.46 & NS \\
\hline Absolute value of height & -1.16 & 0.5 & -2.23 & -0.09 & $\mathrm{~S}$ \\
Height Z-score & -6.29 & 6.39 & -19.32 & 6.74 & $\mathrm{NS}$ \\
Percentage height & 0.05 & 0.88 & -1.79 & 1.89 & $\mathrm{NS}$ \\
Absolute value of weight & -0.49 & 0.45 & -1.43 & 0.44 & $\mathrm{NS}$ \\
Weight Z-score & -27.24 & 17.75 & -63.92 & 9.44 & $\mathrm{NS}$ \\
Percentage weight & 8.85 & 7.66 & -7.61 & 25.33 & $\mathrm{NS}$ \\
LOS & -1.76 & 1.12 & -4.08 & 0.55 & $\mathrm{NS}$ \\
Pre-tx speed of growth & 7.35 & 9.83 & -14.83 & 29.54 & $\mathrm{NS}$ \\
Post-tx speed of growth & 0.15 & 0.18 & -0.23 & 0.54 & NS \\
Complications & & &
\end{tabular}


Table 9. Test di Mann-Whitney: rank sums of the 2 groups subject to different transplants

\begin{tabular}{ll}
\hline & Prob $>1 \mathrm{z}$ \\
\hline Absolute value of height & 0.0430 \\
Height Z-score & 0.0222 \\
Percentage height & 0.0233 \\
Absolute value of weight & 0.875 \\
Weight Z-score & 0.25 \\
Percentage weight & 0.126 \\
LOS & 0.307 \\
Pre-tx speed of growth & 0.096 \\
Post-tx speed of growth & 0.496 \\
Complications & 0.399 \\
\hline
\end{tabular}

\section{Discussion}

Supplying appropriate and intensive nutrition to children who are severely malnourished at hospital admission contributes significantly to the success of transplantation in terms of growth in height and shorter hospital stays.

In our study, the t-test and Mann-Whitney test confirmed the positive effects of nutrition on the growth in height of children receiving intensive nutrition compared with those following a regular oral diet alone, despite the fact that the former were far more malnourished than the latter upon admission, and had an average Z-score of -2.22 \pm 1.97 compared with the average height $Z$-score of $0.54 \pm 2.29$ in Group 1 .

Furthermore, our data confirmed the greater effectiveness of intensive nutrition in shortening the length of hospital stay among females and younger patients, thus confirming the results of other studies (Renz et al., 2001; Bartosh, Thomas, Sutton, Brady, \& Whitington; Saito et al., 2007). In some studies (Alonso, 2008; Bartosh et al., 1999; Saito et al., 2007), the mean height $Z$-score of the population waiting for liver transplantation ranged between -1.0 and -1.75 . The mean height $Z$-score of the 34 children in our study, which was $-1.30 \pm 2.11$ at admission, was within this range.

This mean value decreases if we consider that 19 of our children had a height between the $3^{\text {rd }}$ and $10^{\text {th }}$ percentile upon admission, and a mean height Z-score of $-2.22 \pm 1.97$. These children (Group 0) followed an intensive nutrition protocol in the pre-transplant period, achieving a height Z-score of $-1.95 \pm 2.74$ at the time of transplantation. So there was a slight improvement of the growth in height (from -2.22 to -1.95 ), though the values remained in the negative range.

Despite intensive nutrition, growing in height is unquestionably difficult in the pre-transplant phase because of pathologies that prevent achieving "normal" standards.

Shepherd et al. (1991), followed by Alonso (2008), observed that despite the intensive supply of calories, many children affected with cirrhosis and advanced chronic hepatitis fail to achieve normal growth, and their functions may continue to deteriorate, making transplantation the only possible solution.

The children in Group 1 whose statural and ponderal growth at admission was above the $25^{\text {th }}$ percentile had a height $\mathrm{Z}$-score of $0.54 \pm 2.29$. These children followed a controlled oral diet in the pre-transplant period, reaching a height $Z$-score of $1.1 \pm 1.84$ at the time of transplantation.

Linear regression analysis has confirmed that intensive nutrition therapy is more effective because it shortens the length of hospital stay for younger children. According to Saito et al. (2007), children below the age of two years affected with biliary tract atresia tend to grow faster despite severe pre-transplant malnutrition. According to Renz (2001) who divided his study population into 3 groups, as had Tanner et al. (1966), there are significant differences in terms of height Z-score and velocity of growth Z-score in the posttransplant period. He also emphasized the potential advantages of performing early liver transplantation during periods in which endocrinologic variables favor accelerated growth. Bartosh et al. (1999), in contrast with Codoner- Franch et al. (1994) believe that the best time to perform a transplant is not determined solely by age.

According to the data, gender affects the length of hospital stay and growth (McDiarmid et al., 1999). On one hand, the average hospital stay for females is 24.5 (coefficient value) days longer than for males; on the other 
hand, intensive nutritional therapy has proven to be more effective in decreasing the days of hospitalization $(\mathrm{p}=$ 0.023 ) and increasing the growth in height and weight (mean= $-1,65$ and $-47,32$ ) among female patients. Comparing our outcomes with those in the literature (Renz et al., 2001), male patients experienced a minor delay in height growth at the time of transplantation, and a greater velocity of growth compared to female patients, while others (McDiarmid et al., 1999) have found no statistical significance in gender for affecting the height growth curve after transplantation.

Intensive nutrition therapy enables the blocking of metabolic, endocrinologic, and immune-related alterations triggered by the organism in case of stress caused by a pathology or surgical procedure (Ingenbleek \& Bernstein, 1999). According to Spada et al. (2009), the high rate of successful transplants is strongly affected by the possibility of scheduling the transplant before the onset or development of critical clinical conditions and severe malnutrition. Although the linear regression coefficient of intensive nutrition does not indicate statistically significant values related to the impact of intensive nutrition on length of hospital stay, it is important to underline that this approach still achieves positive results. This means that the length of stay is shorter for children treated with intensive nutrition. Although De Russo (2007) believes that intensive nutrition improves growth and survival potential when adopted in a timely fashion, and in a quantitatively and qualitatively correct manner, he administered intensive nutrition to only $47.8 \%$ of the malnourished patients in his study and to $36 \%$ of them only a few days before the surgical procedure or discharge.

Fourteen $(41.2 \%)$ of the 34 children in our study did not experience any complications during the ten months after transplantation. The remaining 58.8\% experienced complications, with 7 children experiencing more than one complication, thus requiring longer hospital stays.

Three children (8.8\%) died: 1 of cardiac arrest 7 days after transplant, and 2 of superinfections approximately 2-3 months after transplantation. In order not to skew the statistical analysis, the length of hospital stay of the three deceased children was considered "very long" (more than 10 months). The overall post-transplant survival rate was $91.2 \%$.

Among the 34 patients there were 3 cases of portal vein thrombosis, frequently associated with biliary atresia secondary to preexistent hypoplasia, and immediately solved by thrombectomy; 3 cases of stenosis followed by thrombosis of the hepatic artery; and 4 cases of acute cell rejection confirmed by biopsy, and treated with high dose steroid therapy. Of these 4 cases, the sole child affected with mild rejection was treated only by increasing tacrolimus blood levels.

Three children experienced biliary stenosis, which has a frequency of $10-30 \%$ and can depend on the anatomical and perfusional characteristics of the donor graft (Spada, Riva, Maggiore, Cintorino, \& Gridelli, 2009).

Infection-related complications are the most common and troublesome cause of post-transplant morbidity and mortality because of the presence of venous and vesical catheters, a lower immune defense secondary to immunosuppression, and the characteristics of the donor graft. Two children died of bacterial and fungal infections, 2 suffered from bacterial infections and 2 from viral infections. According to Bucuvalas et al. (2004), infectious complications during the initial post-transplant period significantly affect the short and long term success of transplantation. Saito et al. (2007) state that the complication that most affects the velocity of growth in height is hepatic vein stenosis, because it is difficult to arrive at an early diagnosis compared with other vascular stenoses and with biliary stenosis.

The results of this analysis regard the subgroups with and without complications, and confirm the relevance and usefulness of intensive nutrition therapy. In fact, by applying the two tests to the subgroup without complications (7 children from Group 0, and 7 children from Group 1) it can be seen that the percentage height increased in the group receiving intensive nutrition (Tables 6 and 7), and that the height Z-score increased in the subgroup with complications ( 8 children in Group 0, and 18 children in Group) (Table 6).

Twenty-nine of the 34 children received standard immunosuppression as per our protocol (basiliximab + metilprednisolone + tacrolimus). Only 5 patients received non standard immunosuppression (basiliximab + metilprednisolone + tacrolimus). Three of these 5 children were coadminstered mycophenolate: 2 were coadminstered cyclosporine, and 1 coadminstered lamivudine.

Renz et al. (2001) compared 2 groups following two different immunosuppression protocols ( $\mathrm{ACp}=$ azathioprine, cyclosporine, prednisone; $\mathrm{CNp}=$ mycophenolate, cyclosporine, prednisone) and found no significant differences between the two groups in terms of height and velocity of growth. In our analysis, the only statistically significant outcomes were the ones achieved by the group following the standard immunosuppression protocol: the children receiving intensive nutrition grew more in height (mean $Z$-score $=-1.64$ and $\mathrm{P}>0.0070$ ) compared 
to the children receiving oral nutrition (Tables 6 and 7).

It is known that exposure to steroids delays children's growth (Alonso, 2008; Saito et al., 2007). In fact, most current immunosuppression protocols do not envisage the use of steroids (Spada et al., 2006; Sarna, Sipila, Vihervuori, Koistinen, \& Holmberg, 1995) except in cases of severe acute rejection or autoimmune hepatitis. In our study, the differences between the mean height Z-scores measured in the subgroup that did not receive steroids (10 children in Group 0, and 16 in Group 1) showed that the group receiving intensive nutrition grew more in height. The same applies to the rank sums of the Mann-Whitney test (Tables 4 and 5).

To be underlined is the fact that statistically significant outcomes were also achieved by the subgroup receiving steroid therapy and intensive nutrition (5 children in Group 0 , and 3 in Group 1), namely an increase in height Z-score and body weight among the children subject to intensive nutrition therapy. This outcome, as in the case of complications, substantiates the importance of adopting an intensive nutrition strategy.

In our study, the statistically significant results showed a height increase associated with cadaveric split-liver transplantation (segments II-III) compared to other types of transplant, while Renz et al. (2001) found no statistically significant difference between the height scores and velocity of growth among recipients of grafts from living donors, cadaveric split-liver donors, or whole-organ donors. This outcome further confirms that the split-liver technique has improved and is now comparable to the other techniques (McDiarmid, Anand, \& Lindblad, 2004; Utterson et al., 2005; Bilik, Greig, Langer, \& Superina, 1993; Whitington \& Balistreri, 1991). The first split-liver procedures performed on segments II and III use to imply a longer hepatic ischemia time, thus affecting the outcomes of the transplant itself, with a high difficulty of recovery of the grafted organ (Spada et al., 2009).

\section{References}

Alonso, E. M. (2008). Growth and developmental considerations in pediatric liver transplantation. Liver Transplantation, 14, 585-591. http://dx.doi.org/10.1002/lt.21488

Barshes, N. R., Chang, I. F., Karpen, S. J., Carter, B. A., \& Goss, J. A. (2006) Impact of pretransplant growth retardation in pediatric liver transplantation. Journal of Pediatric Gastroenterology and Nutrition, 43, 89-94. http://dx.doi.org/10.1097/01.mpg.0000226378.03247.1f

Bartosh, S. M., Thomas, S. E., Sutton, M. M., Brady L. M., \& Whitington, P. F. (1999). Linear growth after pediatric liver transplantation. The Journal of Pediatrics, 135, 624-631. http://dx.doi.org/10.1016/S0022-3476(99)70062-4

Bilik, R., Greig, P., Langer, B., \& Superina R. A. (1993). Survival after reduced-size liver transplantation is dependent on pretransplant status. Journal of Pediatric Surgery, 28, 1307-1311. http://dx.doi.org/10.1016/S0022-3468(05)80318-5

Bourdeaux, C., Tri, T. T., Gras, J., Sokal, E., Otte, J. B., de Ville de Goyet, J., \& Reding, R. (2005). PELD score and posttransplant outcome in pediatric liver transplantation: a retrospective study of 100 recipients. Transplantation, 79, 1273-6.

Bucuvalas, J. C., Zeng, L., \& Anand, R. (2004). Studies of Pediatric Liver Transplantation Research Group Predictors of length of stay for pediatric liver transplant recipients. Liver Transplantation, 10, 1011-1017. http://dx.doi.org/10.1002/lt.20203

Campos, A. C., Matias, J. E., \& Coelho, J. C. (2002). Nutritonal aspect of liver transplantation. Current Opinion in Clinical Nutrition \& Metabolic Care, 5, 297-307.

Codoner-Franch, P., Bernard, O., \& Alvarez, F. (1994). Long-term follow-up of growth in height after successful liver transplantation. The Journal of Pediatrics, 124, 368-373. http://dx.doi.org/10.1016/S0022-3476(94)70357-4

De Russo, P. A., Ye, W., \& Shepherd, R. (2007). Biliary Atresia Research Consortium Growth failure and outcomes in infants with biliary atresia: A report from the biliary atresia Consortium. Hepatology, 46, $1632-1638$.

Falcão, M. C., \& Tannuri, U. (2002). Nutrition for the pediatric surgical patient: approach in the peri-operative period. Revista do Hospital das Clinicas de Faculdade de Medicina da Universidade de Sao Paulo, 57, 299-308. http://dx.doi.org/10.1590/S0041-87812002000600010

Giammanco, M., Caldiero, G., Raimondo, D., Sammartano, A., Frazzetta, M., Vetri, G., \& Di Gesù, G. (2003). Artificial nutrition for the treatment of short bowel syndrome. Minerva Chirurgica, 58, 545-549. 
Greer, R., Lehnert, M., Lewindon, P., Cleghorn, G. J., \& Shepherd, R. W. (2003). Body composition and components of energy expenditure in children with end-stage liver disease. Journal of Pediatric Gastroenterology and Nutrition, 36, 358-363.

Heubi, J. E., Helman, M. B., Melvin, B., \& Shulman, R. J. (2002). The impact of liver disease on growth and nutrition. Journal of Pediatric Gastroenterology and Nutrition, 35, S55-S59. http://dx.doi.org/10.1097/01.MPG.0000017850.43290.6B

Holt, R. I., Miell, J. P., Jones, J. S., Mieli-Vergani, G., \& Baker, A. (2000). Nasogastric feeding enhances nutritional status in paediatric liver disease but does not alter circulating level of IGF-I and IGF binding proteins. Clinical Endocrinology, 52, 217-224. http://dx.doi.org/10.1046/j.1365-2265.2000.00934.x

Ingenbleek, Y., \& Bernstein, L. (1999). The successful condition as nutritionally-dependent adaptive dichotomy. Nutrition, 15, 305-320. http://dx.doi.org/10.1016/S0899-9007(99)00009-X

Johnson, R. C., Young, S. K., Cotter, R., Lin, L., \& Rowe, W. B. (1990). Medium-chain-triglyceride lipid emulsion: metabolism and tissue distribution. American Journal of Clinical Nutrition, 52, 502-508.

Lai, H., \& Chen, W. (2000). Effects of medium-chain and long-chain triacylglycerols in pediatric surgical patients. Nutrition, 16, 401-406.

Marchesini, G., Fabbri, A., Bianchi, G., Brizi, M., \& Zoli, M. (1996). Zinc supplementation and amino acid-nitrogen metabolism in patient with advanced cirrhosis. Hepatology, 23, 1084-1092. http://dx.doi.org/10.1002/hep.510230523

McDiarmid, S. V., Anand, R., \& Lindblad, A. S. (2004). Studies of Pediatric Liver Transplantation:An overview of demographics, indications, timing, and immunosuppressive practices in pediatric liver transplantation in the United States and Canada. Pediatric Transplantation, 8, 284-294. http://dx.doi.org/10.1111/j.1399-3046.2004.00153.x

McDiarmid, S. V., Gornbein, J. A., DeSilva, P. J., Goss, J. A., Vargas, J. H., Martín, M. G., .. Busuttil, R. W. (1999). Factors affecting growth after pediatric liver transplantation. Transplantation, 67, 404-411.

McDiarmid, S. V., Merion, R. M., Dykstra, D. M., \& Harper, A. M. (2004a). Selection of pediatric candidates under the PELD system. Liver Transplantation, 10 (10 suppl. 2), S23-30. http://dx.doi.org/10.1002/lt.20272

Novy, M. A., \& Schwarz, K. B. (1997). Nutritional consideration and management of the child with liver disease. Nutrition, 13, 177-184. http://dx.doi.org/10.1016/S0899-9007(97)00045-2

Ramaccioni, V., Soriano, U., Arumugam, R., \& Klish, W. J. (2000). Nutritional aspects of chronic liver disease and liver transplantation in children. Journal of Pediatric Gastroenterology \& Nutrition, 30, 361-367.

Renz, J. F., de Roos, M., Rosenthal, P., Mudge, C., Bacchetti, P., Watson, J., ... Emond, J. C. (2001). Posttransplantation growth in pediatric liver recipients. Liver Transplantation, 7, 1040-1055. http://dx.doi.org/10.1053/jlts.2001.29413

Saito, T., Mizuta, K., Hishikawa, S., Kawano, Y., Sanada, Y., Fujiwara, T., ... Kawarasaki, H. (2007). Growth curves of pediatric patients with biliary atresia following living donor liver transplantation: Factors that influence post transplantation growth. Pediatric Transplantation, 11, 764-770. http://dx.doi.org/10.1111/j.1399-3046.2007.00744.x

Sarna, S., Sipila, I., Vihervuori, E., Koistinen, R., \& Holmberg, C. (1995). Growth delay after liver transplantation in childhood: studies of underlying mechanisms. Pediatric Research, 38, 366-372. http://dx.doi.org/10.1203/00006450-199509000-00016

Shepherd, R. W. (1996). Pre- and postoperative nutritional care in liver transplantation in children. Journal of Gastroenterology and Hepathology, 11, 7-10. http://dx.doi.org/10.1111/j.1440-1746.1996.tb00283.x

Shepherd, R. W., Chin, S. E., Cleghorn, G. J., Patrick, M., Ong, T. H., Lynch, S. V., ... Strong, R. (1991). Malnutrition in children with chronic liver disease accepted for liver transplantation: clinical profile and effect on outcome. Journal of Paediatrics and Child Health, 27, 295-299. http://dx.doi.org/10.1111/j.1440-1754.1991.tb02541.x

Spada, M., Petz, W., Bertani, A., Riva, S., Sonzogni, A., Giovannelli, M., ... Gridelli, B. (2006). Randomized trial of basiliximab induction versus steroid therapy in pediatric liver allograft recipients under tacrolimus immunosoppression. American Journal of Transplantation, 6, 1913-1921. http://dx.doi.org/10.1111/j.1600-6143.2006.01406.x 
Spada, M., Riva, S., Maggiore, G., Cintorino D., \& Gridelli B. (2009). Pediatric liver transplantation. World Journal of Gastroenterology, 15, 648-674. http://dx.doi.org/10.3748/wjg.15.648

Tanner, J. M., Whitehouse, R. H., \& Takaishi, M. (1966). Standards from birth to maturity for height, weight, heigh velocity and weight velocity. British children, 1965, Part II. Archives of Disease in Childhood, 41, 613-635. http://dx.doi.org/10.1136/adc.41.220.613

Utterson, E. C., Shepherd, R. W., Sokol, R. J., Bucuvalas, J., Magee, J. C., McDiarmid, S. V., ... Split Research Group. (2005). The split research Group Biliary atresia: clinical profiles, risk factors, and outcomes of 755 patients listed for liver transplantation. The Journal of Pediatrics, 147, 180-185. http://dx.doi.org/10.1016/j.jpeds.2005.04.073

Whitington, P. F., \& Balistreri, W. F. (1991). Liver transplantation in pediatrics: indications, contraindications, and pretransplant management. The Journal of Pediatrics, 118, 169-177. http://dx.doi.org/10.1016/S0022-3476(05)80478-0 